\title{
Experimental Study on the Axial Compression of Short Basalt Fiber Reinforced Concrete Columns with Spiral Stirrups
}

\author{
Wang Xinzhong ${ }^{1,2_{*}}$, Li Chuanxi ${ }^{1}$, Zhou Wei ${ }^{2}$ and Xie Heliang ${ }^{2}$ \\ ${ }^{1}$ School of Civil Engineering and Architecture, Changsha University of Science \& Technology, Changsha, 410114, China \\ ${ }^{2}$ School of civil engineering, Hunan City University, Yiyang, 413000, China
}

Received 1 December 2016; Accepted 1 February 2017

\begin{abstract}
Short reinforced concrete (RC) column with spiral stirrups is an important component of civil engineering. However, the usability and durability of short RC columns are affected significantly by concrete cracking, poor adaptive deformability, low toughness and acid-base corrosion. Improving the stress performance of short RC columns is favour of normal application. Adding basalt fiber into concrete is an important method to improve the stress performance of short RC columns. Effects of basalt fiber on the axial compressive mechanical properties of short RC columns with spiral stirrups were explored in this study. The optimal fiber length and content were determined by a cube test of basalt fiber concrete. An axial compression experiment was conducted by preparing six pieces of short basalt fiber reinforced concrete (BFRC) columns with spiral stirrups and six pieces of short RC columns with spiral stirrups. Results showed that the ultimate bearing capacities of all short BFRC columns with spiral stirrups were larger ( $28.5 \%$ up to the most) than those of the short RC columns with spiral stirrups. The short BFRC columns with spiral stirrups developed cracks and fall of their protective layers later than the short RC columns with spiral stirrups. Basalt fiber can improve the ultimate strain of concrete and significantly improve the adaptive deformability of short RC columns. Research results prove that basalt fiber can improve the bearing capacity and usability of the short RC column with spiral stirrups. Conclusions are valuable for the extensive application of basalt fiber to the civil engineering.
\end{abstract}

Keywords: Spiral stirrup, Basalt fiber, Short column, Axial compression

\section{Introduction}

Short reinforced concrete $(\mathrm{RC})$ column with spiral stirrups is one of the most important components of civil engineering. Stress performance and bearing capacity of short RC column are crucial to safety of the overall structure. However, the normal use and durability are significantly affected by poor flexural strength, shrinkage cracking, low toughness, low shock resistance of concrete and environmental corrosion. Therefore, increasing usability of the short RC column with spiral stirrups by improving properties of the concrete has been explored comprehensively. Adding fiber is an effective method. Most of existing researches have described the addition of steel fiber, glass fiber, synthetic fiber, basalt fiber, and carbon fiber into concrete structures [1], [2], [3], [4]. Basalt fiber is highly appreciated for the high tensile strength, high modulus of elasticity, strong corrosion resistance, good chemical stability, and environmental-friendly properties. Several studies have reported that adding basalt fiber in concrete structures according to certain proportions could enhance the acid-base corrosion resistance and toughness of the concrete structures [5], [6], [7], [8], [9]. Therefore, adding basalt fiber concrete in RC structures instead of plain concrete can improve the mechanical performance and durability of RC structures. Existing researches on the use of basalt fiber in concrete structures mainly focus on improving basic mechanical properties of the concrete. The associated

E-mail address: wxz0419314@163.com

ISSN: 1791-2377 C 2017 Eastern Macedonia and Thrace Institute of Technology. All rights reserved. applications are still in the testing stage. Only a few studies have investigated the compression supporting member of RC. To promote the application of basalt fiber in RC structures, it is very necessary to explore the axial compressive mechanical performance of short basalt fiber RC (BFRC) columns with spiral stirrups. In this study, the optimal length and content of basalt fiber were determined through an experimental investigation. An axial compressive test using six pieces of short BFRC columns with spiral stirrups was carried out. Subsequently, effects of basalt fiber on the bearing capacities of short RC columns under axial compression were discussed by a contrastive analysis.

\section{State of the art}

Basalt fiber reinforced concrete is constructed by adding certain proportions of chopped basalt fiber into concrete. Abundant researches on the mechanical performance of basalt fiber reinforced concrete (BFRC) have been reported. Ramakrishnan et al.[10] studied the slumps, workability, liquidity, and early cracking behavior of concrete structures with different contents of basalt fiber. They found that the concrete structure with $0.5 \%$ (volume fraction) of basalt fiber maintain good workability. Basalt fiber can significantly reduce the early shrinkage of concrete structures. Adding a certain amount of basalt fiber can reduce concrete cracks by as high as $98 \%$. Borhan et al.[11] studied concrete compression strength with different contents of basalt fiber. They discovered that concrete 
compression strength increases when basalt fiber content (volume fraction) increases from $0 \%$ to $0.3 \%$, but decreases by $12 \%$ when basalt fiber content (volume fraction) further increases to $0.5 \%$. Kabay studied the cracking resistance and wear resistance of concrete structures with different contents of basalt fiber, concluding that even low basalt fiber content can increase the intensity of toughness, crack resistance, and wear resistance of concrete structures[12]. Based on a quasistatic flexural experiment, Asprone[13] pointed out that basalt fiber can enhance the toughness of mortar. Mortar with basalt fiber presents stronger toughness and higher sensitivity to strain rate compared to plain mortar. These research results have demonstrated that a reasonable content of basalt fiber can enhance mechanical properties of the concrete structure. They have laid the groundwork for studying effects of basalt fiber on enhancement of compression members of RC. The application of basalt fiber in RC columns has been reported by a few studies. AlBaijat[14] tested the influences of basalt fiber content on the compression failure of concrete structures, the buckling of steel sections, and the debonding performance of the steel-concrete interface section of composite steel-concrete columns. The results demonstrated that the structural behavior and strength of BFRC columns could be improved significantly by increasing the basalt fiber content (\%). Min Hou[15] discussed effects of basalt fiber content on the physical and mechanical parameters of three recycled concrete structures with different recycled aggregate replacement ratios $(0 \%, 50 \%$, and $100 \%)$, and then carried out a contrastive analysis about mechanical properties of short recycled concrete axial compression columns with different basalt fiber contents. The results showed that basalt fiber is superior to common concrete in term of enhancement of recycled concrete structures. Furthermore, basalt fiber can be used to enhance the mechanical properties of recycled concrete structures and corresponding short columns.
Through an experimental study on 18 pieces of square BFRC eccentric compression columns, Wang Xinzhong et al.[16] disclosed that basalt fiber can increase the largeeccentric ultimate bearing capacity of RC structures by $41 \%$. These studies have confirmed the effectiveness of basalt fiber in improving mechanical properties of RC structures and the bearing capacity and ductility of short concrete column. However, no comprehensive study on applications of basalt fiber in short RC column with spiral stirrups has been reported yet. Short RC column with spiral stirrups is a common component of structural engineering. Therefore, studying influences of basalt fiber on mechanical properties of such RC column is of great significance to promote engineering applications of basalt fiber. In this study, an axial compression test using six pieces of short RC columns with spiral stirrups and six pieces of short BFRC columns with spiral stirrups was conducted. The differences between short BRFC columns and short RC columns were analyzed.

The rest of this study is organized as follows. Section 3 introduces the methodology, including the proportion of concrete mix, parameters and optimal content of basalt fiber materials, short column design, and test program. Section 4 is the analysis and discussion of test results, as well as the test characteristics and differences between BRFC columns and RC columns. Section 5 is conclusions.

\section{Methodology}

\subsection{Test materials and mix proportion}

Two proportions of concrete mix were used in this experiment (Table1). The cement (P.O 42.5) used the ordinary Portland cement which has a continuous secondary gravel grading diameter of $5-26.5 \mathrm{~mm}$ and a crushing value of 10.5. The fineness modulus of sand was 2.85. Tap water without any water-reducing agent was used.

Table 1. Proportions of concrete mix

\begin{tabular}{l|l|l|l|l|l|l}
\hline Proportions & Concrete Strength & Water-binder ratio (\%) & Cement $\left(\mathbf{k g} \cdot \mathbf{m}^{-3}\right)$ & Water $\left(\mathbf{k g} \cdot \mathbf{m}^{-3}\right)$ & Sand $\left(\mathbf{k g} \cdot \mathbf{m}^{-3}\right)$ & $\mathbf{G r a v e l}\left(\mathbf{k g} \cdot \mathbf{m}^{-\mathbf{3}}\right)$ \\
\hline 1 & C30 & 0.55 & 355 & 195 & 703 & 1147 \\
2 & C40 & 0.49 & 398 & 195 & 614 & 1193 \\
\hline
\end{tabular}

The chopped basalt fiber produced by Zhejiang Hengdian Shijin Basalt Fibre Co., Ltd. was used in this study.
Five different lengths of basalt fiber were tested to determine the optimal length (Fig.1). The experimental parameters are shown in Table 2.

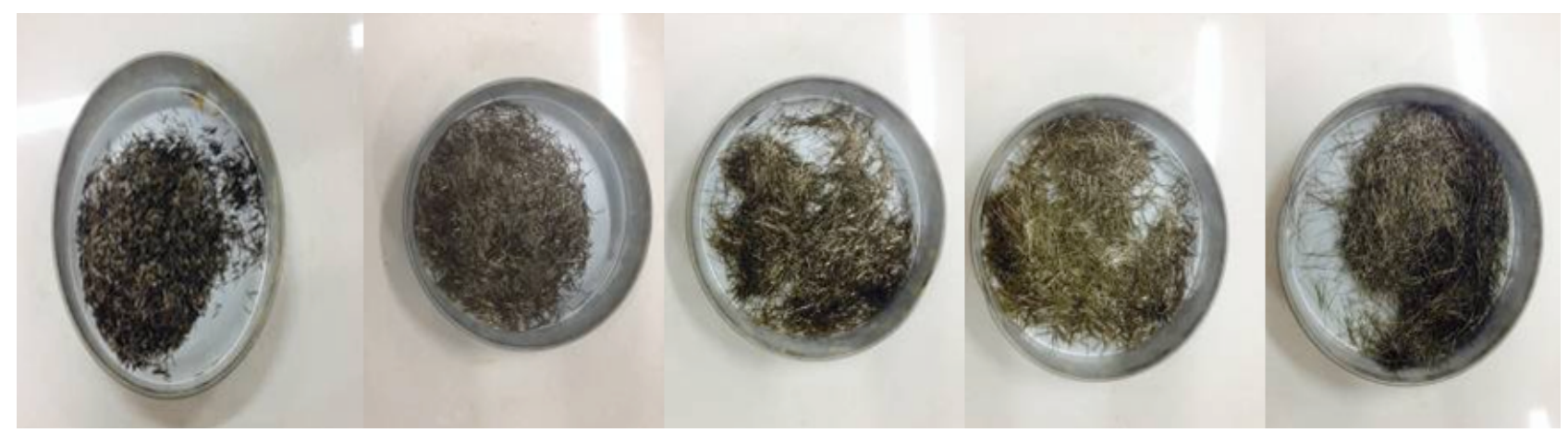

Fig. 1. Basalt fiber of different lengths

Table 2. Basalt fiber parameters

\begin{tabular}{|c|c|c|c|c|}
\hline Fiber diameter $(\mu \mathrm{m})$ & Fiber length (mm ) & Fiber density $\left(\mathrm{kg} \cdot \mathrm{m}^{-3}\right)$ & Tensile strength (MPa) & Elasticity modulus (MPa) \\
\hline 17 & 12 & 2650 & 3000 & 90 \\
\hline 17 & 18 & 2650 & 3000 & 90 \\
\hline 17 & 24 & 2650 & 3000 & 90 \\
\hline 17 & 30 & 2650 & 3000 & 90 \\
\hline 17 & 36 & 2650 & 3000 & 90 \\
\hline
\end{tabular}


A total of 24 groups of specimens with $0.075 \%$ and $0.1 \%$ (volume fraction) basalt fiber were prepared. Each group consists of three specimens. The standard specimen maintenance is shown in Fig. 2. The cube compressive

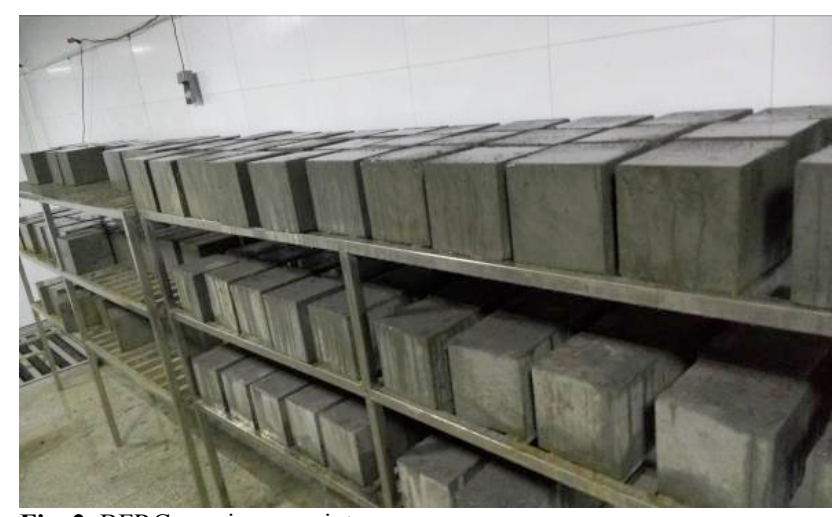

Fig. 2. BFRC specimen maintenance strengths of 24 specimens of two proportions at the $7 \mathrm{~d}$ and $28 \mathrm{~d}$ were tested. The test program is illustrated in Fig. 3. The results are listed in Table 3 and Table 4.

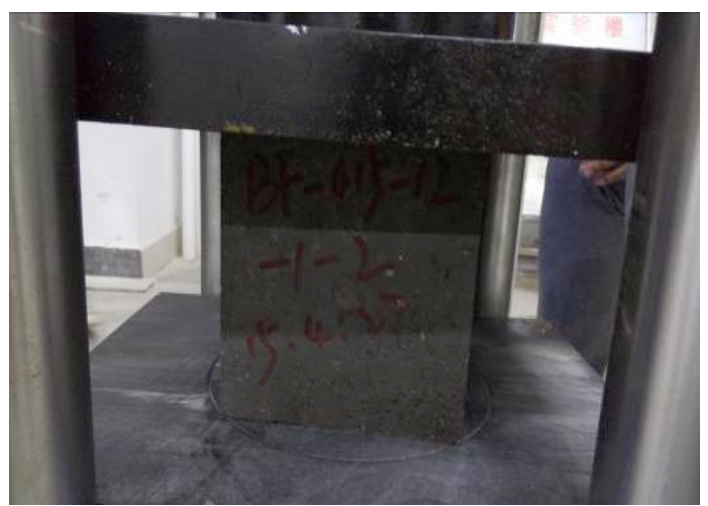

Fig. 3. Cube compressive strength test of specimen

Table 3. Cube comprehensive strength of $0.075 \%$ BFRC specimen

\begin{tabular}{|c|c|c|c|c|c|c|c|c|}
\hline \multirow{3}{*}{$\begin{array}{c}\text { Length } \\
(\mathrm{mm})\end{array}$} & \multicolumn{4}{|c|}{ 7d } & & \multicolumn{3}{|c|}{ 28d } \\
\hline & \multicolumn{2}{|c|}{$\mathrm{C30}$} & \multicolumn{2}{|c|}{$\mathrm{C40}$} & \multicolumn{2}{|c|}{ C30 } & \multicolumn{2}{|c|}{$\mathrm{C40}$} \\
\hline & $f_{\mathrm{cc}}(\mathrm{MPa})$ & $\alpha(\%)$ & $f_{\mathrm{cc}}(\mathrm{MPa})$ & $\alpha(\%)$ & $f_{\mathrm{cc}}(\mathrm{MPa})$ & $\eta(\%)$ & $f_{\mathrm{cc}}(\mathrm{MPa})$ & $\eta(\%)$ \\
\hline 0 & 26.7 & 80.2 & 31.3 & 75.8 & 33.3 & 0 & 41.3 & 0 \\
\hline 12 & 26.5 & 77.0 & 32.1 & 70.7 & 41.1 & 23.4 & 45.4 & 9.9 \\
\hline 18 & 26.9 & 74.3 & 32.3 & 73.7 & 36.2 & 8.7 & 43.8 & 6.1 \\
\hline 24 & 24.5 & 70.0 & 32.9 & 73.8 & 35 & 5.1 & 44. 6 & 8.0 \\
\hline 30 & 28.4 & 76.3 & 34.0 & 76.7 & 37.2 & 11.7 & 44.3 & 7.3 \\
\hline 36 & 25.4 & 70.8 & 32.4 & 75.2 & 35.9 & 7.8 & 43.1 & 4.4 \\
\hline
\end{tabular}

Table 4. Cube comprehensive strength of $0.1 \%$ BFRC specimen

\begin{tabular}{|c|c|c|c|c|c|c|c|c|}
\hline \multirow{3}{*}{$\begin{array}{l}\text { Length } \\
\text { (mm) }\end{array}$} & \multicolumn{4}{|l|}{$7 d$} & \multicolumn{4}{|l|}{ 28d } \\
\hline & \multicolumn{2}{|l|}{ C30 } & \multicolumn{2}{|l|}{$\mathrm{C40}$} & \multicolumn{2}{|l|}{ C30 } & \multicolumn{2}{|l|}{$\mathrm{C40}$} \\
\hline & $f_{\text {cc }}($ MPa $)$ & $\alpha / \%$ & $f_{\mathrm{cc}}(\mathrm{MPa})$ & $\alpha(\%)$ & $f_{\mathrm{cc}}(\mathrm{MPa})$ & $\eta(\%)$ & $f_{\mathrm{cc}}(\mathrm{MPa})$ & $\eta(\%)$ \\
\hline 0 & 26.7 & 80.2 & 31.3 & 75.8 & 33.3 & 0 & 41.3 & 0 \\
\hline 12 & 25.4 & 61.8 & 30.3 & 73.0 & 37.4 & 12.3 & 44.5 & 7.7 \\
\hline 18 & 27.9 & 79.9 & 29.0 & 63.5 & 34.9 & 4.8 & 45.7 & 10.7 \\
\hline 24 & 24.8 & 69.9 & 30.9 & 70.4 & 35.9 & 7.8 & 43.9 & 6.3 \\
\hline 30 & 27.2 & 80.2 & 30.6 & 71.5 & 33.9 & 1.8 & 42.8 & 3.6 \\
\hline 36 & 29.6 & 81.5 & 30.9 & 67.9 & 36.3 & 9.0 & 45.5 & 10.2 \\
\hline
\end{tabular}

Note: $\alpha \%$ is $7 \mathrm{~d} f_{\mathrm{cc}} / 28 \mathrm{~d} f_{\mathrm{cc}} ; \eta \%$ is growth of $28 \mathrm{~d} f_{\mathrm{cc}}$ of BFRC specimen and $28 \mathrm{~d} f_{\mathrm{cc}}$ RC specimen

Table 3 and Table 4 show that the cube compressive strength of the BFRC specimen at $28 \mathrm{~d}$ is higher than that of the RC specimen. The optimal fiber length is $12 \mathrm{~mm}$.

The experiment to determine the optimal basalt fiber content used the first proportion of concrete mix. The experiment covered two different lengths of basalt fiber
$(12 \mathrm{~mm}$ and $24 \mathrm{~mm})$. The volume fractions of basalt fiber about the test specimens were $0.075 \%, 0.1 \%, 0.15 \%, 0.2 \%$, $0.25 \%, 0.3 \%$ and $0.4 \%$ respectively. A total of 52 groups of specimens were produced. Each group has three specimens. All specimens were treated via standard maintenance. Test results are listed in Table 5 and Table 6.

Table 5. Results of cube compressive strength test on the C30 BFRC specimen

\begin{tabular}{|c|c|c|c|c|c|c|c|c|}
\hline \multirow{3}{*}{$\begin{array}{l}\text { Basalt fiber } \\
\text { content }(\%)\end{array}$} & \multicolumn{4}{|l|}{$7 d$} & \multicolumn{4}{|l|}{ 28d } \\
\hline & \multicolumn{2}{|c|}{ Fiber length $=12 \mathrm{~mm}$} & \multicolumn{2}{|c|}{ Fiber length $=24 \mathrm{~mm}$} & \multicolumn{2}{|c|}{ Fiber length $=12 \mathrm{~mm}$} & \multicolumn{2}{|c|}{ Fiber length $=24 \mathrm{~mm}$} \\
\hline & $f_{\mathrm{cc}}(\mathrm{MPa})$ & $\alpha(\%)$ & $f_{\mathrm{cc}}(\mathrm{MPa})$ & $\alpha(\%)$ & $f_{\mathrm{cc}}(\mathrm{MPa})$ & $\eta(\%)$ & $f_{\mathrm{cc}}(\mathrm{MPa})$ & $\eta(\%)$ \\
\hline 0 & 26.7 & 80.2 & 26.7 & 80.2 & 33.3 & 0 & 33.3 & 0 \\
\hline 0.075 & 26.5 & 61.8 & 24.5 & 70.0 & 41.1 & 23.4 & 35.0 & 5.1 \\
\hline 0.1 & 25.4 & 70.5 & 24.8 & 69.9 & 37.4 & 12.3 & 35.9 & 7.8 \\
\hline 0.15 & 29.4 & 62.5 & 26.2 & 72.6 & 41.7 & 25.2 & 37.4 & 12.3 \\
\hline 0.20 & 25.3 & 66.7 & 26.8 & 71.8 & 40.5 & 21.6 & 37.3 & 12.0 \\
\hline 0.25 & 25.0 & 75.3 & 25.0 & 68.5 & 37.5 & 12.6 & 36.5 & 9.6 \\
\hline 0.30 & 26.5 & 73.0 & 26.6 & 78.9 & 35.2 & 5.7 & 33.7 & 1.2 \\
\hline 0.40 & 25.9 & 77.0 & 24.6 & 73.7 & 35.5 & 6.6 & 33.4 & 0.3 \\
\hline
\end{tabular}

Note: $\alpha \%$ is $7 \mathrm{~d} f_{\text {cc }} / 28 \mathrm{~d} f_{\text {cc }} ; \eta \%$ is growth of $28 \mathrm{~d} f_{\text {cc }}$ of BFRC specimen and $28 \mathrm{~d} f_{\text {cc }}$ RC specimen.

Table 6. Results of splitting strength and flexural strength test on the C30 BFRC specimen

\begin{tabular}{|c|c|c|c|c|c|c|c|c|}
\hline \multirow{3}{*}{$\begin{array}{l}\text { Basalt fiber } \\
\text { content (\%) }\end{array}$} & \multicolumn{4}{|c|}{ Fiber length $=12 \mathrm{~mm}$} & \multicolumn{4}{|c|}{ Fiber length $=24 \mathrm{~mm}$} \\
\hline & \multicolumn{2}{|c|}{ Splitting strength at 28d } & \multicolumn{2}{|c|}{ Flexural strength at 28d } & \multicolumn{2}{|c|}{ Splitting strength at 28d } & \multicolumn{2}{|c|}{$\begin{array}{l}\text { Flexural strength at 28d } \\
\end{array}$} \\
\hline & $f_{\text {ts }}(\mathrm{MPa})$ & $\begin{array}{ll}\begin{array}{l}\text { Growth } \\
(\%)\end{array} & \text { rate } \\
\end{array}$ & $f_{\mathrm{f}}(\mathrm{MPa})$ & $\begin{array}{ll}\text { Growth rate } \\
(\%)\end{array}$ & $f_{\text {ts }}(\mathrm{MPa})$ & $\begin{array}{ll}\text { Growth rate } \\
(\%)\end{array}$ & $f_{\mathrm{f}}(\mathrm{MPa})$ & $\begin{array}{ll}\begin{array}{l}\text { Growth rate } \\
(\%)\end{array} \\
\end{array}$ \\
\hline $\begin{array}{l}0 \\
0.075 \\
0.1\end{array}$ & $\begin{array}{l}3.77 \\
3.91 \\
4.07\end{array}$ & $\begin{array}{l}0 \\
3.71 \\
7.96\end{array}$ & $\begin{array}{l}5.24 \\
5.44 \\
6.08\end{array}$ & $\begin{array}{l}0 \\
3.81 \\
16.1\end{array}$ & $\begin{array}{l}3.77 \\
3.95 \\
4.17\end{array}$ & $\begin{array}{l}0.00 \\
4.77 \\
10.61\end{array}$ & $\begin{array}{l}5.24 \\
5.54 \\
6.18\end{array}$ & $\begin{array}{l}0.00 \\
5.73 \\
17.94\end{array}$ \\
\hline
\end{tabular}




\begin{tabular}{l|l|l|l|l|l|l|l|l|l|l}
0.15 & 4.27 & 13.26 & 5.84 & 11.49 & 4.37 & 15.92 & 13.36 \\
0.20 & 4.15 & 10.08 & 5.53 & 5.56 & 4.25 & 12.73 & 5.63 \\
0.25 & 3.95 & 4.77 & 5.46 & 4.25 & 3.99 & 5.84 & 5.54 \\
0.30 & 3.89 & 3.18 & 5.39 & 2.93 & 3.89 & 3.18 & 6.30 \\
0.40 & 3.82 & 1.33 & 5.35 & 2.09 & 3.85 & 2.12 & 5.79 \\
\hline
\end{tabular}

It can be seen from Table 5 and Table 6 that the optimal basalt fiber content is $0.15 \%$. The corresponding cube compressive strengths of the C30 BFRC specimens $(12 \mathrm{~mm}$ and $24 \mathrm{~mm}$ ) increase by $25.2 \%$ and $12.3 \%$, respectively. Therefore, short BFRC columns were prepared by adding $0.15 \%$ (volume fraction) $12 \mathrm{~mm}$ long basalt fiber into concrete.

\subsection{Short column design and test program}

Two lengths $(1.20 \mathrm{~m}$ and $0.60 \mathrm{~m})$ of short column specimens were used in this experiment. All specimens comprise eight pieces of $12 \mathrm{~mm}$-long longitudinal steel bars and spiral stirrups (diameter $=6 \mathrm{~mm}$ ) at an interval of $60 \mathrm{~mm}$. The protective layers of the reinforcing steel bars were $10 \mathrm{~mm}$ thick (Fig. 4). $12 \mathrm{~mm}$ HRB400 twisted steel bars were used as the longitudinal bars, while HRB335 round steel bars (diameter $=6 \mathrm{~mm}$ ) were used as the stirrups. According to GT/B288.1-2010 Tensile Test for Metal Materials: Part I----- Room Temperature Test, the yield strengths of the longitudinal bars and stirrups were tested $486 \mathrm{MPa}$ and $360.1 \mathrm{MPa}$, and their tensile strengths were tested $590 \mathrm{MPa}$ and $570.4 \mathrm{MPa}$, respectively. The first proportion of concrete mix was applied for the short RC columns and short BFRC columns. The short BFRC columns contained $0.15 \%$ (volume fraction) $12 \mathrm{~mm}$ long basalt fibers.

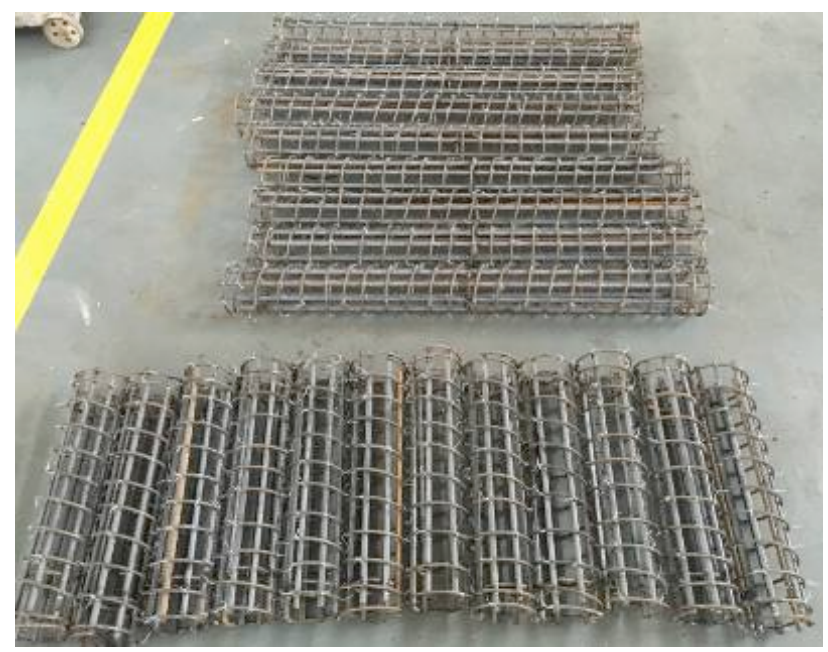

Fig. 4. Reinforcing steel bars for short test columns

The experiment using one-way repeated loadingunloading was implemented in the Structural Engineering Laboratory of the School of Architecture and Construction, Hunan City University. Each specimen was preloaded by 20 $\mathrm{kN}$, which was kept for 3 min to observe the reliability of the loading system and measurement points. Unloading and official loading began subsequently. The official loading started with the gradation loading. The $1.20 \mathrm{~m}$ columns were loaded by $20 \mathrm{kN}$ at each grade, and each grade of loading

was maintained for 2 min until the final failure of the columns. At each grade, the $0.60 \mathrm{~m}$ columns were loaded by $40 \mathrm{kN}$ firstly and then by $20 \mathrm{kN}$ after the cracking or heaving of the column. Each loading grade was maintained for 2 min until the final failure of the columns. The loading site is presented in Fig. 5.

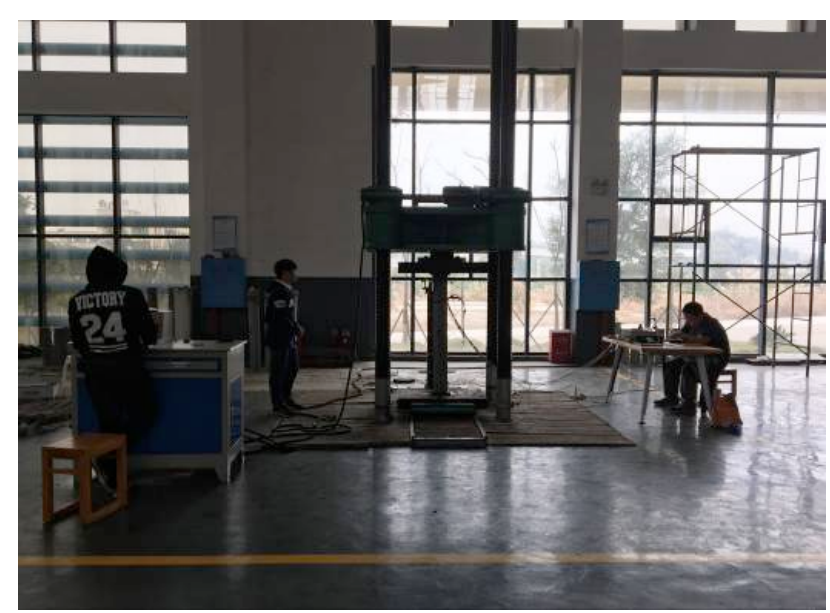

Fig. 5. Loading site

\section{Analysis of results and discussions}

\subsection{Experimental phenomena}

The experiment witnessed a gradual expansion and increase of cracks, fall of the protective layer, increased displacement, failure of the core concrete structure, and loading up to peak as time progressed. The short RC columns produced the first crack at $540-560 \mathrm{kN}$, whereas the short BFRC columns produced the first crack at $620-640 \mathrm{kN}$. The protective layers of the short RC columns fell at $580-620 \mathrm{kN}$, and the protective layers of the short BFRC columns fell at $780-820$ $\mathrm{kN}$. The short BFRC columns had cracks and the fall of protective layer earlier than the short RC columns. The failure morphologies of specimens are shown in Fig. 6.

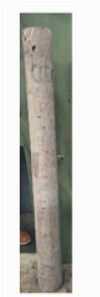

RC-L-1

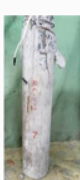

RC-D-1

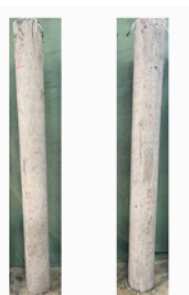

RC-L-2 RC-L-3

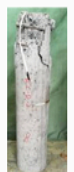

RC-D-2

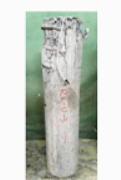

RC-D-3

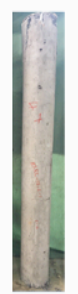

BFRC-L-1

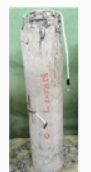

BFRC-D-1 BFRC-D-2

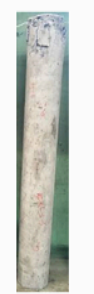

BFRC-L-3

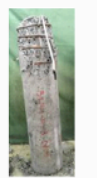

BFRC-D-3
Fig. 6. Failure morphologies of short column specimens

\subsection{Test results}

Test results of the short columns are shown in Table 7. The short BFRC columns have significantly higher (28.5\% up to the most at $200 \mathrm{kN}$ ) ultimate bearing capacity than the short RC columns. The short BFRC columns with different lengths of basalt fiber have similar ultimate bearing capacities. Basalt fiber increases the bearing capacity of the short RC columns, confirming its effectiveness in improving 
the concrete compression strength. The growth rate of the axial compressive strength is higher than that of the cube compressive strength, indicating that basalt fiber enhances not only concrete strength, but also the collaborative effect of reinforcing steel bars and fiber concrete. In the axial compression test, the comprehensive strength utilization of the reinforcing steel bars increased at the ultimate bearing capacity of the concrete structure before the yield failure of reinforcing steel bars. The addition of basalt fiber increases the compressive strengths of the reinforcing steel bars and concrete to the maximum extent.

Table 7. Experimental results of short test columns under axial compression

\begin{tabular}{|c|c|c|c|c|c|}
\hline No. & Specimen No. & Basalt fiber content $(\%)$ & $\begin{array}{l}\text { Fiber length } \\
(\mathrm{mm})\end{array}$ & Axial length (m) & $\begin{array}{c}\text { Ultimate bearing capacity } \\
(\mathrm{KN})\end{array}$ \\
\hline 1 & RC-L-1 & 0 & 1 & 1.25 & 700 \\
\hline 2 & RC-L-2 & 0 & 1 & 1.25 & 680 \\
\hline 3 & RZ-L-3 & 0 & l & 1.25 & 680 \\
\hline 4 & BFRC-L-1 & $0.15 \%$ & 12 & 1.25 & 880 \\
\hline 5 & BFRC-L-2 & $0.15 \%$ & 12 & 1.25 & 880 \\
\hline 6 & BFRC-L-3 & $0.15 \%$ & 12 & 1.25 & 860 \\
\hline 7 & RC-D-1 & 0 & 1 & 0.6 & 680 \\
\hline 8 & RC-D-2 & 0 & 1 & 0.6 & 700 \\
\hline 9 & RZ-D-3 & 0 & / & 0.6 & 700 \\
\hline 10 & BFRC-D-1 & $0.15 \%$ & 12 & 0.6 & 880 \\
\hline 11 & BFRC-D-2 & $0.15 \%$ & 12 & 0.6 & 880 \\
\hline 12 & BFRC-D-3 & $0.15 \%$ & 12 & 0.6 & 900 \\
\hline
\end{tabular}

\subsection{Load-displacement curve}

It can be seen from the load-displacement curves (Fig.7) that there's no significant difference between the short RC columns and short BFRC columns in the beginning of the experiment. As the loading process continues, protective layers of the short BFRC columns fall later than those of the short RC columns. After the fall of protective layers and before the ultimate bearing capacity, the short BFRC columns produce a far larger displacement than the short RC columns, indicating basalt fiber not only enhances concrete strength and ductility as well as the coordinated deformation of reinforcing steel bars and concrete, but also increases the bearing capacity and adaptive deformability of short columns after falls of protective layers.

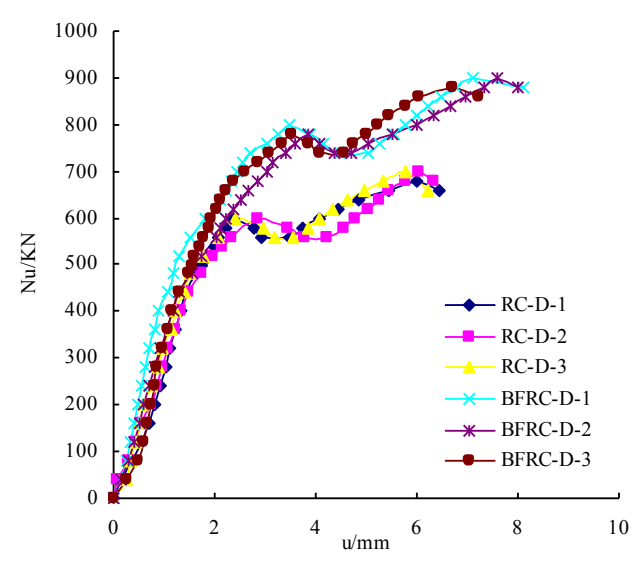

Fig. 7. Load-vertical displacement curves

\subsection{Load-strain curve}

In Fig. 8, the load-strain curves of the short BFRC columns and short RC columns are similar in the beginning of the experiment. As the loading process continues, concrete of the short RC column begins to fall when the strain was close

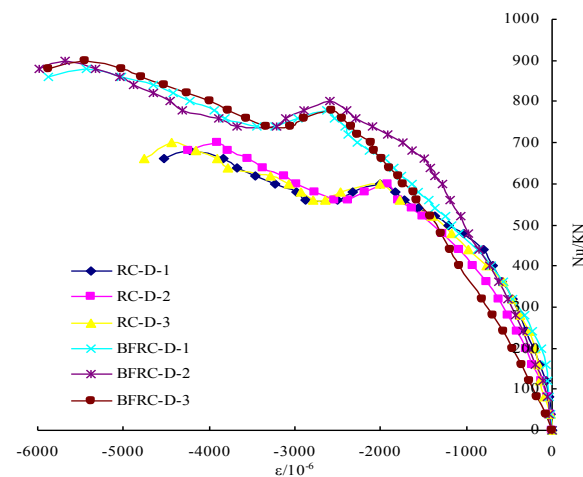

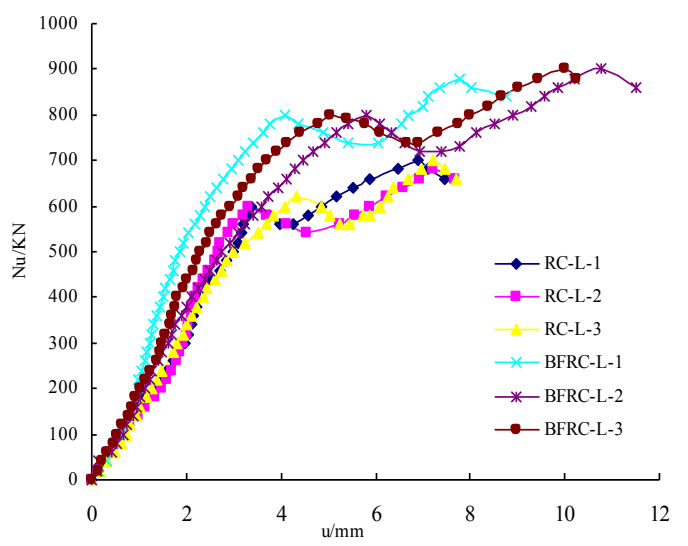

to $\varepsilon=0.002$, and the core concrete fails at $\varepsilon=0.0035-0039$. Concrete of the short BFRC column begins to fall at $\varepsilon=0.0025-0.0028$, and the core concrete breaks down at $\varepsilon=0.005-0.006$. The ultimate strain of the basalt fiber concrete in the short BFRC columns is slightly larger than that of the concrete in the short RC columns.

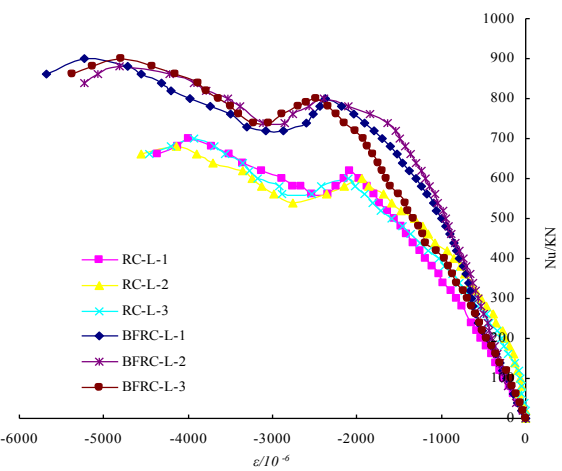

Fig. 8. Load-strain curves of core concrete in short columns 


\section{Conclusions}

An axial compression test using short BFRC columns with optimal fiber length and content is carried out in order to explore the effects of basalt fiber on mechanical properties and usability of short RC columns with spiral stirrups. The short BFRC columns are compared with the short RC columns to determine effects of basalt fiber on the axial compression strength of short RC columns. The following conclusions are drawn:

(1) The short BFRC columns have significantly higher ultimate bearing capacity than the short RC columns. With the increase of loads in the experiment, the short BFRC columns develop cracks, fall of protective layers and peak loads later than the short RC columns, indicating that basalt fiber can enhance the axial compressive strength of short RC columns.

(2) In the experiment, no longitudinal reinforcing steel bars in short columns yield, and the ultimate strain of concrete in the BFRC columns is far higher than that of concrete in the RC columns. Therefore, the short BFRC columns maximize the compressive strengths of reinforcing steel bars.

(3) The short BFRC columns develop larger displacement at the ultimate bearing capacity compared to the short RC columns. The basalt fiber improves the adaptive deformability and ductility of the short RC columns significantly.

The experiment on the short columns with different lengths shows that basalt fiber can increase the ultimate bearing capacity of short RC columns. Similar to the short $\mathrm{RC}$ columns, the short BFRC columns in the study show concrete failure instead of yield failure of the reinforcing steel bars. The compressive strengths of the reinforcing steel bars are underused. Future research will explore the optimal reinforcement ratio of short BFRC columns for the sake of engineering design and application promotion.

\section{Acknowledgements}

This work was supported by the 973 Project of Ministry of Science of the People's Republic of China (Grant No. 2015CB057701).

This is an Open Access article distributed under the terms of the Creative Commons Attribution Licence

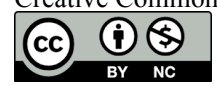

\section{References}

1. H. M. O. Al-Baijat. "The Use of Basalt Aggregates in Concrete Mixes in Jordan”. Jordan Journal of Civil Engineering, 2(1), 2008, pp.63-70.

2. Sayyed Mahdi Abtahi, Mohammad Sheikhzadeh, Sayyed Mahdi Hejazi. "Fiber-reinforced asphalt-concrete-A review", Construction and Building Materials, 24, 2010, pp.871-877

3. Xie Ergai, Li Zhongying. "Application Prospect of Basalt Fiber". FIBERCOMPOSITES, 2003, pp.317-320

4. Hannant, D. J., "Fiber reinforced concrete". In: Newman J, Choo BS, editors. Advanced concrete technology-processes, Oxford: An Imprint of Elsevier, 2003, pp.146-163.

5. NAJAFI M.,KHALILI,S. M. R.,ESLAMI-FARSANI R., "Hybridization Effect of Basalt and Carbon Fibers on Impact and Flexural Properties of Phenolic Composites". Iranian Polymer Journal, 2014, 23 (10), pp.767-773.

6. Dylmar Penteado Dias, Clelio Thaumaturgo. "Fracture toughness of geopolymeric concretes reinforced with basalt fibers". Cement \& Concrete Composites, 27, 2005, pp.49-54.

7. Wang Mingchao, Zhang Zuoguang, Sun Zhijie, Li Min. "Corrosion resistance characteristic of continuous basalt fiber and its reinforcing composites". Journal of Beijing University of Aeronautics and Astronautics, 32(10),2006, pp.1255-1258.

8. JIN Shengji, LI Zhongliang, ZHANG Jian, WANG Yanling. "Experimental Study on Anti-freezing and Thawing Performance of Reinforced Concrete of Basalt Fiber under Corrosion Condition". Engineering Mechanics, 32(5), 2015, pp.178-183

9. HUANG Kaijian, DENG Min. "Stability of basalt fibers in alkaline solution and its effect on the mechanical property of concrete". Acta Materiae Compositae Sinica, 27(1), 2010, pp.150-154

10. Ramakrishnan V., Neeraj S. Tolmare,et al. "Performance Evaluation of 3-D Basalt Fiber Reinforced Concrete and Basalt Rod Reinforced Concrete". NCHRP-IDEA Program Project Final Report. Transportation Research Board, Washington, DC, 1998.

11. Tumadhir, Merawi Borhan. "Properties of Glass Concrete Reinforced with Short Basalt Fiber". Materials and Design, 2012, 42(12), pp.265-271.

12. JONG sung Sim, Cheolwoo Park, Do Young Moon. "Characteristics of basalt fiber as a strengthening material for concrete structures". Composites Part B, 36(6), 2005, pp.504-512.

13 ASPRONE, D., CADONI, E., IUCOLANO, F., "Analysis of The Strain rate Behavior of a Basalt Fiber Reinforced Natural Hydraulic Mortar". Cement \& Concrete Composites, 53 (10), 2014, pp.52-58.
14. Hamadallah Al-Baijat, Andrea Benedetti, "Comparison between Composite Column Using Limestone and Basalt Concrete". Open Journal of Civil Engineering, 3(1), 2013, pp.1-6.

15. HOU Min, DONG Jiangfeng, YUAN Shucheng, WANG Qingyuan. "Experimental Research of Mechanical Properties of Basalt Fiber Aggregate Concrete and Its Short Columns under Axial Compression". Journal of North China Institute of Water Conservancy and Hydroelectric Power, 34 (1), 2013, pp.41-45.

16. WANG Xinzhong, LI Chuanxi. "Experimental Study on LoadCarrying Capacity of Basalt Fiber Reinforced Concrete Long Columns under Eccentric Compression". Bulletin of the Chinese Ceramic Society, 35(10), 2016, pp.3242-3246. 